Original Research Article

\title{
Antimicrobial prescribing patterns in surgical inpatient of tertiary care hospital in Eastern India
}

\author{
Sumit Kumar Gupta1, Siddhartha Ghosh ${ }^{2 *}$
}

${ }^{1}$ Department of Surgery, IQ City Medical College and hospital, Durgapur, West Bengal, India ${ }^{2}$ Department of Pharmacology, IQ City Medical College and hospital, Durgapur, West Bengal, India

Received: 12 June 2019

Revised: 29 June 2019

Accepted: 06 July 2019

*Correspondence to:

Dr. Siddhartha Ghosh, Email: drsiddharthaghosh83@ gmail.com

Copyright: (c) the author(s), publisher and licensee Medip Academy. This is an openaccess article distributed under the terms of the Creative Commons Attribution NonCommercial License, which permits unrestricted noncommercial use, distribution, and reproduction in any medium, provided the original work is properly cited.

\begin{abstract}
Background: Antimicrobials form the cornerstone of prescriptions for treating infection. Surgical management cannot be possible without the use of antibiotics. Severity of infection, suspected spectrum of organisms and their sensitivity, comorbidities of the patient, route of antibiotic administration are the important parameter to consider before selecting antibiotic.

Methods: Cross-sectional, hospital based, descriptive study was conducted in the ward of Surgery Department of IQ City Medical college, Durgapur over a period of 1 year. The relevant information was entered into the pretested preformats (containing name, age, sex, diagnosis, ongoing treatment as recorded from patients' prescription slips or CRFs) and analyzed. Necessary permission was granted by the Institutional Ethical Committee and written informed consent was obtained from the patients prior to collecting their prescription slips/CRF.

Results: Commonest cause of hospitalization was cholelithiasis (318 (32.7\%)). Antimicrobials were the most commonly prescribed drugs (1626 (31.6\%)). Single antibiotic prescribing frequency are similar to two antibiotic prescribing (both $44 \%$ ). Piperacillin+Tazobactum combination most commonly prescribe antibiotic.
\end{abstract}

Conclusions: Beta lactam antibiotic specifically Piperacillin (ATC class: J01D) were the most commonly prescribed antibiotic agents both before and after surgical procedures.

Keywords: Antimicrobial, Cholelithiasis, Piperacillin, Prescription, Polypharmacy, Standard treatment guideline

\section{INTRODUCTION}

Infection is one of the common causes of morbidity and mortality in today's world. It is also a common cause of hospital admission, more so in surgery inpatient. So antimicrobial drugs became more important and commonly used drugs in surgical inpatient. Antimicrobials form the cornerstone of prescriptions for treating infection. Surgical management cannot be completed without the use of antimicrobial and analgesic drugs. Irrational prescription may lead to severe postoperative complications. This group of drugs are considered as the second most commonly prescribed drugs in the world, only second to the drugs indicated for cardiovascular diseases. ${ }^{1}$

Any deviation from standard treatment guideline (STG) or evidence based prescribing of antibiotic in respect of indication, dose, duration or frequency lead irrational prescription. Irrational antibiotic prescription leads to polypharmacy, increase expanses for drugs, preference of branded medicine over generic medicine and excessive 
use and misuse of antimicrobials. ${ }^{2-5}$ All these increases financial burden on patient family primarily, immediately and directly.

Irrational antibiotic use also result in increased incidence of adverse drug reactions, delay in cure, increased hospital stay, increasing resistance to antimicrobials. All these leads to much deleterious, longstanding effect on society by increasing morbidity and mortality, and financial burden on health system. ${ }^{6-7}$ Increase incidence of multidrug resistant (MDR) pathogens made antibiotic prescription more challenging. ${ }^{8}$ Severity of infection, suspected spectrum of organisms and their sensitivity, comorbidities of the patient, route of antibiotic administration are the important parameter to consider before selecting antibiotic.

Rational antibiotic use require proper selection of antimicrobial agent, dosing, route, and duration of therapy .Proper use of antimicrobial helps in clinical cure or prevention of infection as well as limit the unintended consequences, such as the emergence of resistance, adverse drug events and cost. ${ }^{9}$

\section{METHODS}

An observational, Prospective analytical study was done in the department of General Surgery \& Pharmacology of IQ City Medical College, Durgapur, West Bengal during the period of April 2018 to April 2019, only after obtaining an approval from Institutional Ethical Committee.

\section{Inclusion Criteria}

- Patients admitted in the department of general surgery.

- Both male and female patients in the age group of 1075 years are included in the study.

\section{Exclusion Criteria}

- Patients having severe systemic diseases like uncontrolled diabetes mellitus, renal failure, chronic liver disease, immune compromised patients etc are excluded.

- Patients having acute cholecystitis or any acute surgical condition are excluded.

\section{The Data Collection method}

- $\quad$ Patient admitted in the department of general surgery were included in the study based on the inclusion/exclusion criteria.

- Bed head ticket (BHT) of the hospital record (case record forms [CRFs]) were randomly collected. The relevant information was entered into the pretested preformats (containing name, age, sex, diagnosis, ongoing treatment as recorded from patients' prescription slips or CRFs) and analyzed.

Analysis done by the help of SPSS and Microsoft Excels 2010

\section{RESULTS}

Out of 970 cases, $500(51.5 \%)$ were males and 470 $(48.5 \%)$ were females. Most of the cases were in the age group of 40-60 yrs (410cases, $42.2 \%$ ) followed by between the age of 21 and 40 years (310 cases, 31.9\%),(160 cases, $16.4 \%$ ) were in the age 60 years or more, while least number of cases 11 to 20 years of age (90 cases, $9.2 \%$ ) . Commonest cause of hospitalization was cholelithiasis $(318(32.7 \%))$, followed by acute appendicitis (150 $(15.7 \%))$. Other disorders constituted 120 (12.3\%) in which each disorder was less than $1 \%$ of the total diagnosis Figure 1.

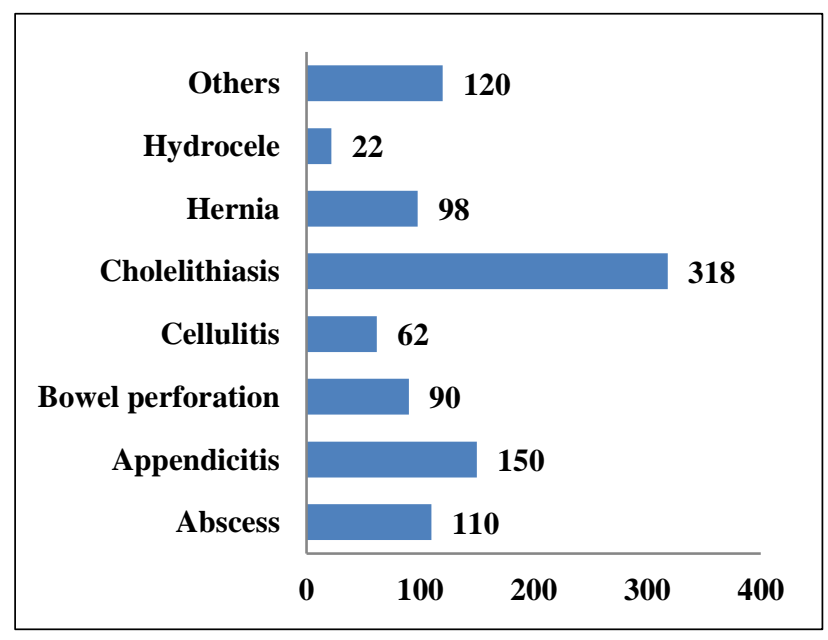

Figure 1: Distribution of disease in surgery inpatient.

A total of 5141 drugs were prescribed to the 970 cases, giving an average number of drugs per prescription of 5.3 (median 5). Most preferred route of drug administration was intravenous route (4113 drugs, 80\%) followed by oral (771 drugs, 15\%) and intramuscular (257 drugs, 5.0\%) route. Antimicrobials were the most commonly prescribed drugs (1626 (31.6\%)) followed by non-steroidal antiinflammatory drugs (NSAIDs), which constituted $1337(26 \%)$.

Single antibiotic prescribing frequency are similar to two antibiotic prescribing (both 44\%). Only $12 \%$ prescription contain 3 antibiotic at a time. (Figure 2) Piperacillin+Tazobactum combination most commonly prescribe antibiotic overall as well in single antibiotic therapy. In two antibiotic therapy Ceftriaxone+Metronidazole commonly prescribe combination. Metronidazole+Amikacin either with cefraxone or Piperacillin+Tazobactum preferred in triple antibiotic therapy (Table 1). 
Table 1: Antibiotic prescribing pattern.

\begin{tabular}{|l|l|}
\hline Single antibiotic & No \\
\hline Piperacillin+Tazobactum & 200 \\
\hline Amoxycillin+Clavulinic Acid & 97 \\
\hline Meropenem & 23 \\
\hline Cefotaxime & 1 \\
\hline Ceftriaxone & 106 \\
\hline Two Antibiotic & \\
\hline Ceftriaxone+Metronidazole & 137 \\
\hline Piperacillin+Tazobactum+Metronidazole & 121 \\
\hline Ceftriaxone+Amikacin & 17 \\
\hline Amoxycillin+Clavulinic Acid+Metronidazole & 30 \\
\hline Ceftriaxone+Tazobactum+Metronidazole & 50 \\
\hline Clindamycin+Levofloxacin & 9 \\
\hline Clindamycin+Tigecycline & 8 \\
\hline Co-Amoxyclav+Amikacin & 7 \\
\hline Linezolid+Clindamycin & 5 \\
\hline Meropenem+Metronidazole & 37 \\
\hline Piperacillin+Tazobactum+Co-amoxyclav & 9 \\
\hline Three Antibitic & \\
\hline Piperacillin+Tazobactum+Metronidazole+Amikacin & 50 \\
\hline Piperacillin+Tazobactum+Metronidazole+Netilmycin & 4 \\
\hline Ceftriaxone+Tazobactum+Metronidazole+Amikacin & 9 \\
\hline Ceftriaxone+Sulbactum+Metronidazole+Amikacin & 50 \\
\hline
\end{tabular}

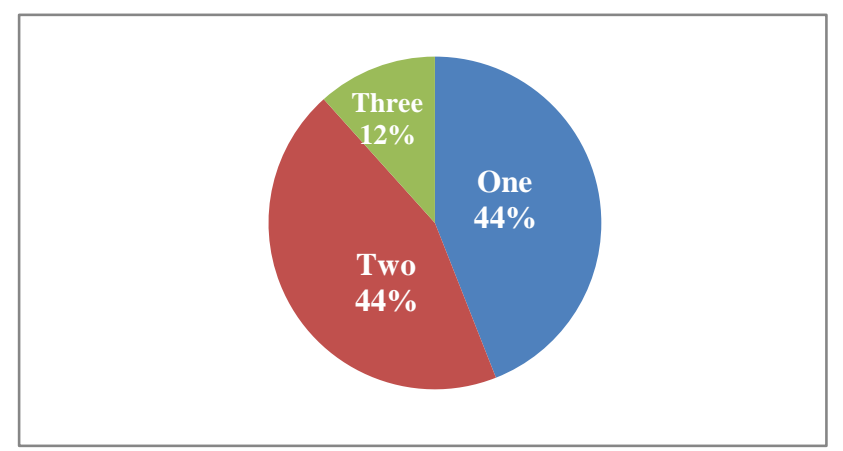

Figure 2: Number of antibiotic per prescription.

\section{DISCUSSION}

Prescription is a reflection of the attitude of physician towards the disease and treatment. It also gives a clear picture of health care delivery system. ${ }^{10}$ Antibiotics are the cornerstone of treatment for infectious diseases. There is inadequate development in novel antibiotic molecule in last three decades. Inadvertent, irrelevant, inadequate use of antimicrobial leads to resistance against current antimicrobial. Urgent promotion of rational use of antimicrobials is not an option but the mandate in current scenario.

Early clinical diagnosis followed by optimal specimen collection helps in early empirical antibiotic application. And early microbiological confirmation helps in narrow spectrum specific antibiotic use. ${ }^{11}$ In this study, antimicrobial prescribing patterns in surgical departments of a privet tertiary care hospital of eastern india was studied. Most of the cases are between $41 \mathrm{yr}$ to $60 \mathrm{yr}$ (410cases, $42.2 \%)$. This is unlike to the study of Ajay khade et al, where the productive age group was primarily involved. ${ }^{12}$ In this study older age group are more involved, so chances of morbidity are much higher. This also justify usage of higher, broad spectrum antibiotic. Use of single and two antimicrobials agents were common (44\%)] followed by three antimicrobial agents [12\%] use . Over prescription of antibiotics along with inappropriate use is leads to risk of resistance, adverse drug reactions and increased cost of therapy. ${ }^{13}$ The excessive use of parenteral route is common practice in most of the developing countries. ${ }^{14}$ This is in par with this study all antibiotics given by intravenous route. Most of antibiotic were prescribed brand names 1414(86.6\%) with only few 212 $(13.4 \%)$ prescribed in their generic names. Increasing pressure from pharmaceutical companies and also antibiotic primarily marketed by their brand names, most of the prescribers do not have much option in this opinion. Prescription of antibiotic in their generic names helps in the identification of the products, making it easier for the prescribers to choose between other alternatives competing in terms of quality, price or convenience..$^{15,16}$

Among single antimicrobial, preferred drugs was Ceftriaxone. Among FDCs, Piperacillin+Tazobactum and Amoxicillin+Clavulanic acid were common (Table 
1).Overall, beta lactam antibiotic specifically Piperacillin (ATC class: J01D) were the most commonly prescribed antibiotic agents both before and after surgical procedures. Most of the antimicrobials prescribed were approved by the drug regulatory bodies and were included in the NLEM and WHO-EML ( $81 \%)$.

Limitation of this study: Authors are not assesed by the WHO prescribing indicators as these are designed for use in primary health centers, dispensaries or hospital outpatient departments. The prescribing indicators are less useful in specialty inpatient clinics in referral hospitals where the drug use pattern is more complex. ${ }^{17}$

Funding: No funding sources Conflict of interest: None declared

Ethical approval: The study was approved by the Institutional Ethics Committee

\section{REFERENCES}

1. Tünger O, Dinç G, Ozbakkaloglu B, Atman UC, Algün U. Evaluation of rational antibiotic use. Int $\mathrm{J}$ Antimicrob Agents. 2000;15(2):131-5.

2. Kanakambal S, Murugesh N, Shanthi M. Drug prescribing pattern in a tertiary care teaching hospital in Madurai (Tamilnadu). Ind J Pharmacol. 2001 May 1;33(3):223.

3. Awad AI, Himad HA. Drug-use practices in teaching hospitals of Khartoum State, Sudan. Eur J Clin Pharmacol. 2006 Dec 1;62(12):1087-93.

4. Patel V, Vaidya R, Naik D, Borker P. Irrational drug use in India: a prescription survey from Goa. J Postgrad Med. 2005 Jan 1;51(1):9-12.

5. Mohanty BK, Aswini M, Hasamnis AA, Patil SS, Murty KS, Jena SK. Prescription pattern in the department of medicine in a tertiary care hospital in south India. J clin diagn res. 2010 Feb;3:2047-51.

6. Tripathi KD. Essentials of medical pharmacology. $7^{\text {th }}$ ed. Jaypee Brothers Publishers; 2013:71.

7. Laporte JR, Porta M, Capella DO. Drug utilization studies: a tool for determining the effectiveness of drug use. Br J Clin Pharmacol. 1983 Sep;16(3):301-4.
8. Umadevi S, Kumar S, Joseph NM, Easow JM, Kandhakumari G, Srirangaraj S, Raj S, Stephen S. Microbiological study of diabetic foot infections. Ind J Med Specialit. 2011 Jan 1;2(1):12-7.

9. Leekha S, Terrell CL, Edson RS. General principles of antimicrobial therapy. Mayo Clin Proceedings. 2011 Feb 1;86(2):156-67.

10. Laporte JR. Towards a healthy use of pharmaceuticals. Dev Dialogue. 1985;2:48-55.

11. Alanis AJ. Resistance to antibiotics: are we in the postantibiotic era?. Arch Med Res. 2005 Nov 1;36(6):697705.

12. Khade A, Bashir MS, Sheethal A. Prescription pattern in the department of surgery in a tribal district hospital of Andhra Pradesh, India. Ann Med Health Sci Res. 2013;3(3):438-41.

13. Harmeet SR, Nagarani MA, Moushumi R. A study on the drug prescribing pattern and use of antimicrobial agents at a tertiary care teaching hospital in eastern Nepal. Ind J pharmacol. 1998 May 1;30(3):175-78.

14. Tomson G. Drug utilization studies in Sri LankaTowards an understanding of medicine in society. Kongl Carolinska Medico Chirurgiska Institutet. 1990; I:1-5.

15. Tabish A, Jha RK, Rathod AM, Rathod RM, Gupta KK. Prescribing trend of analgesics in a tertiary health care setup of rural Vidarbha. Res J Pharm Biol Chem Sci. 2012;3(3):566-71.

16. Rahman MS, Begum ZA, Samad MK. Prescribing pattern of non-steroidal anti-inflammatory drugs at outpatient departments of teaching hospitals. Bangl J Pharmacol. 2007;2(1):1-6.

17. Desalegn AA. Assessment of drug use pattern using WHO prescribing indicators at Hawassa University teaching and referral hospital, south Ethiopia: a crosssectional study. BMC Health Services Res. 2013 Dec;13(1):170.

Cite this article as: Gupta SK, Ghosh S.

Antimicrobial prescribing patterns in surgical inpatient of tertiary care hospital in Eastern India. Int J Basic Clin Pharmacol 2019;8:1902-5. 